\title{
Detection of Aflatoxin in Poultry Feed and Feed Materials through Immuno Based Assay from Different Poultry Farms and Feed Factories in Bangladesh
}

\author{
Mahbuba Akter Lubna ${ }^{1 *}$, Mita Debnath ${ }^{2}$ and Farzana Hossaini ${ }^{3}$ \\ ${ }^{I}$ Quality Control Department, Akij food \& Beverage Ltd., Krisnapura, Dhamrai, Dhaka, Bangladesh, ${ }^{2}$ Kazi Farms Poultry Laboratory, Shafiqul Villa, \\ Chandana, Chowrasta, Gazipur, Bangladesh, ${ }^{3}$ Infectious Diseases Division, International Centre for Diarrhoeal Disease Research Bangladesh, Dhaka, \\ Bangladesh.
}

\begin{abstract}
Current study investigated the occurrence of aflatoxin contamination in poultry feed and feed materials in different poultry farms and feed factories in Bangladesh. A total of 100 samples of finished feed and raw feed materials were collected and tested through direct competitive Enzyme-Linked Immunosorbent Assay (ELISA) for total aflatoxin detection. Overall, $97 \%$ samples $(n=97 / 100)$ in our study, were found positive for aflatoxin contamination. Among finished feed categories, layer grower feed contained highest level of aflatoxin with a mean value of $21.64 \mathrm{ppb}$ whereas layer feed was less susceptible for aflatoxin contamination (mean value $9.49 \mathrm{ppb}$ ). Between raw feed materials, maize samples were highly contaminated $(n=15 / 15,100 \%)$ with aflatoxin while $86.67 \%$ soybean samples showed positive result. Twenty one percent $(\mathbf{2 1 \%}$ ) of the samples in our study contained aflatoxin concentration more than the acceptable limit employed by USFDA and many other countries which might pose severe health risk to poultry and human consumer. Proper surveillance and immediate control measures should be taken to ensure safe poultry feed and feed materials.
\end{abstract}

Keywords: Aflatoxin, Poultry Feed, Enzyme-Linked Immunosorbent Assay (ELISA).

\section{Introduction}

Aflatoxin Contamination of poultry feed and raw feed materials is a serious concern throughout the globe ${ }^{1-3}$. Aflatoxins are a group of toxigenic secondary metabolites mainly secreted by some species of Aspergillus and other fungi ${ }^{4}$.This dietary aflatoxins have 18 different analogues among which four are highly recognized, namely B1, B2, G1 and G2 (AFB1, AFB2, AFG1, AFG2 respectively). Analogue B1 and B2 are mainly produced by Aspergillus flavus while $A$. parasiticus can produce all four analogues ${ }^{5}$. Aflatoxin can contaminate a wide variety of food and feed commodities including maize, wheat, cereal grains, peanut, cotton seed meal, oil seed meal, copra meal, sunflower meal, palm kernel meal, dried fruits, rice, spices and nuts ${ }^{6}$. These Aspergilus spp. use the nutrients of food and feed for propagation and proliferation thus reducing nutritional value of the feeds ${ }^{7}$.

This potential mycotoxin gains much attention due to severe economic losses affecting layers, broilers, turkeys, ducklings, and quails ${ }^{8}$. When aflatoxin contaminated feed is consumed by poultry, crucial growth parameters including feed intake rate, feed conversion efficacy, reproductive performance all are compromised, thus leading to lowered growth rate, decreased egg production and hatchability, and increased likelihood of morbidity and mortality ${ }^{9}$. In poultry, a number of diseases are found to be involved in aflatoxin contamination including diarrhea, multifocal hepatic necrosis, weight gain in liver and kidney, biliary hyperplasia, immunosuppression etc. ${ }^{10-11}$. Not only poultry is susceptible to harmful effect of aflatoxin but also human consumers are also at risk. Moreover, after metabolism, aflatoxins or their metabolites can appear in tissue blood, gizzard, breasts, liver and eggs of poultry posing a severe health threat to human consumers ${ }^{12-14}$. Previous studies revealed that aflatoxins have genotoxic, teratogenic and hepatocarcinogenic effect on human $^{15}$. The International Agency for Research on Cancer (IARC, 2002) demonstrated the naturally occurring aflatoxin analogue B1 (AFB1) as a potential carcinogen to human ${ }^{16}$.

Contamination of aflatoxin in foods and feeds varies depending on geographical location, agricultural and agronomic practices, and storage condition ${ }^{17}$. Contamination of feed grains with aflatoxin are quite common in tropical countries like Bangladesh as high temperature and humid condition facilitate the growth of molds and the production of toxins ${ }^{18}$.

Due to harmful effect of this potent toxin, many countries implemented rules and regulation on animal feeds and food items. According to US- Food and Drug Administration (FDA), the permissible limit of aflatoxin for animal feed is $20 \mu \mathrm{g} / \mathrm{kg}$ or 20 $\mathrm{ppb}$. The acceptable limit for human consumption is much lower than the animal feed, with $4 \mu \mathrm{g} / \mathrm{kg}$ for total aflatoxins and $2 \mu \mathrm{g} /$ $\mathrm{kg}$ for $\mathrm{AFB} 1^{19-20}$. Along these lines, present study was designed to explore the occurrence of aflatoxin contamination in poultry feed and feedstuffs available in Bangladesh. 


\section{Materials and Methods}

Sample Collection:

A total of 100 poultry feed samples including finished feed $(n=70)$ and raw feed materials $(n=30)$ were collected from different poultry farms and feed production factories in Bangladesh during eight months period from July, 2017 to February, 2018 and transferred immediately to laboratory for testing. All test procedures were performed in Kazi Farms Poultry Laboratory, Gazipur, Bangladesh. The finish feed samples represented five categories, namely, broiler starter feed $(\mathrm{n}=13)$, broiler grower feed $(\mathrm{n}=18)$, broiler finisher feed $(\mathrm{n}=12)$, layer feed $(\mathrm{n}=12)$, and layer grower feed $(\mathrm{n}=15)$ while raw feed materials represented two categories including maize $(\mathrm{n}=15)$ and soybean $(\mathrm{n}=15)$. In order to achieve reasonably representative result approximately $500 \mathrm{~g}$ of each sample was collected from poultry farms and feed production factories with proper labeling including date, factory name, sampling place and time of collection. All the samples were homogenized and thoroughly ground for analysis.

\section{Sample Preparation:}

The sample was prepared according to the previous study performed by Kehinde et. al. (2014) in Ogun State, Nigeria ${ }^{21}$. Dilution was done into two different ways. One is 5 fold dilution in which ten grams $(10 \mathrm{~g})$ of feed sample or feed ingredient were taken in conical flasks and labelled according to the sampling location. Fifty milliliter $(50 \mathrm{ml})$ of $70 \%$ methanol was added into each flask to extract the aflatoxin in the feed samples. Another dilution was done by following 10 fold dilution in which Five grams $(5 \mathrm{~g})$ of feed or ingredients were taken and fifty milliliter $(50 \mathrm{ml})$ of $70 \%$ methanol was added into each flak to extract the aflatoxin. After few minutes the samples were filtrated by using Millipore filtrate paper into specific labelled test tubes.

\section{Quantification of Total Aflatoxin in Feed Sample:}

The concentration of aflatoxin was analyzed by a direct competitive Enzyme-Linked Immunosorbent Assay (ELISA), which is based on antigen antibody reaction ${ }^{22}$. For the enumeration, Agra Quant ${ }^{\circledR}$ Total Aflatoxin Assay 4/40 Kits (Romer Laboratory Inc. Singapore) was used. Extracted samples were diluted into dilution wells by adding $200 \mathrm{ml}$ of conjugate solution (provided with the kit) with $100 \mathrm{ml}$ of extracted samples. After proper mixing, $100 \mathrm{ml}$ conjugate mixed extract samples were transferred into antibody coated wells and incubated for $15 \mathrm{~min}$ at room temperature. Following incubation, the wells were washed 5 times with deionized water (provided with the kit) and kept dry. Then $100 \mathrm{ml}$ substrate solution was pipetted into the antibody coated wells and incubated at room temperature for another 5 minutes. Then, $100 \mathrm{ml}$ stop solution (provided with the kit) was added into antibody coated wells which changed the color of solution from blue to yellow. Finally, photometric measurement of aflatoxin was done by putting the antibody coated wells in ELISA aflatoxin reader (Chromate Plate Reader-4300/USA) at $405 \mathrm{~nm}, 450 \mathrm{~nm}$ and $630 \mathrm{~nm}$. All data were calculated by using the SPSS version 9.5 (SPSS, Cary, NC, USA) statistical analysis program.

\section{Results and Discussions}

Poultry feed is highly susceptible to numerous pathogenic fungi and mycotoxin contamination. Causative agent of aflatoxin, Aspergillus spp. and their spore are globally distributed in environment and easily contaminate crops, raw feed materials and finished feed ${ }^{23}$. In our study, among five categories of finished feed samples, layer grower feed was most susceptible to aflatoxin contamination with a mean value of $21.64 \mathrm{ppb}$ while layer feed had the lowest aflatoxin level of $9.49 \mathrm{ppb}$. Overall, maximum aflatoxin value and mean value for broiler feed was $77.45 \mathrm{ppb}$ and $17.51 \mathrm{ppb}$, respectively. Among three categories of broiler feed (broiler starter, broiler grower and broiler finisher) broiler finisher showed better result than other two categories with a mean value of $5.25 \mathrm{ppb}$ of mean value of $5.25 \mathrm{ppb}$ of aflatoxin. In case of raw feed materials, $86.67 \%$ samples of soybean showed positive result for aflatoxin while all the maize samples $(100 \%)$ were contaminated with this potential toxin.

Table 1. Frequency of aflatoxin contamination in poultry finished feed and raw feed materials

\begin{tabular}{lcccccc}
\hline FeedSample & $\begin{array}{c}\text { Samples } \\
\text { Analyzed (n) }\end{array}$ & $\begin{array}{c}\text { Positive } \\
\text { Samples (\%) }\end{array}$ & $\begin{array}{c}\text { Maximum } \\
\text { level }(\mathrm{ppb})\end{array}$ & $\begin{array}{c}\text { Minimum } \\
\text { level }(\mathrm{ppb})\end{array}$ & $\begin{array}{c}\text { Mean } \\
(\mathrm{ppb})\end{array}$ & $\begin{array}{c}\text { No of Sample } \\
(>20 \mathrm{ppb})\end{array}$ \\
\hline Broiler Starter & 13 & $12(92.31)$ & 77.45 & 5.63 & 20.06 & 3 \\
Broiler Grower & 18 & $18(100)$ & 57.50 & 6.81 & 17.80 & 4 \\
Broiler Finisher & 12 & $12(100)$ & 58.36 & 5.25 & 14.33 & 2 \\
Layer & 12 & $12(100)$ & 17.05 & 6.31 & 9.49 & 0 \\
Layer Grower & 15 & $15(100)$ & 101.90 & 5.00 & 21.64 & 3 \\
Soybean & 15 & $13(86.67)$ & 74.31 & 5.29 & 22.03 & 4 \\
Maize & 15 & $15(100)$ & 63.66 & 5.52 & 23.47 & 5 \\
\hline
\end{tabular}

$\mathrm{ppb}=$ Parts per billion 
Total sample

Sample>20ppb aflatoxin

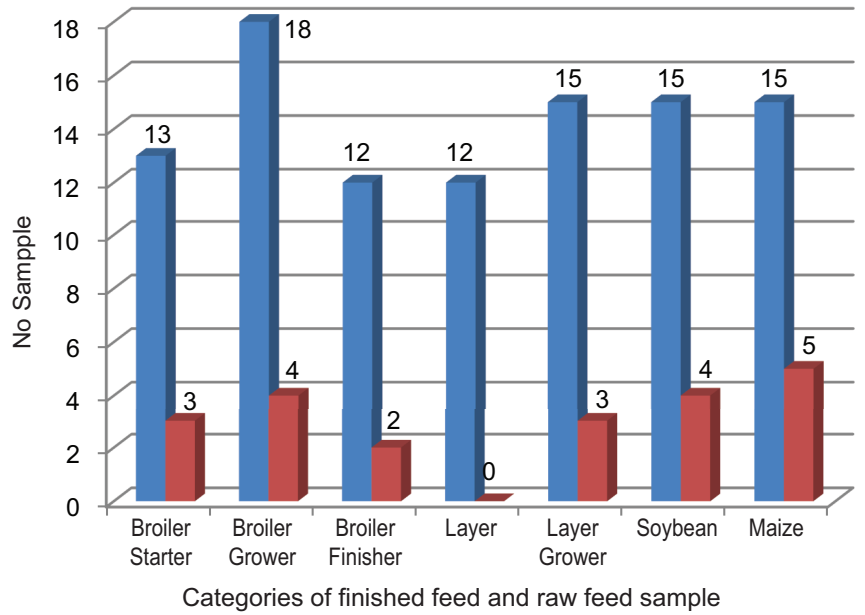

Figure 1. Feed Samples having Aflatoxin concentration more than $20 \mathrm{ppb}$

In our study, as a whole, 97\% samples (finished feed and raw feed materials) were positive with varying concentration level of aflatoxin. Highest value of aflatoxin was $101.90 \mathrm{ppb}$ while mean value of aflatoxin was $18.74 \mathrm{ppb}$ which is more than three times higher than the value found by Nemati et.al. (2014) where he studied 80 poultry feed samples in Iran and found maximum value of aflatoxin was $40 \mathrm{ppb}$ with mean value of $4.90 \mathrm{ppb}^{24}$.

In most cases, quality of finished feed greatly depends on quality of raw feed materials. Contaminated, low qualified raw feed ultimately generates low graded finished feed which is poisonous for both poultry and human consumers. In 2006, Beg et. al., surveyed broiler starter feed, broiler finisher feed, and layer mash feed in Kuwait and found low level of aflatoxin which indicated the good quality of raw feed materials ${ }^{25}$.

The level of aflatoxin in raw feed materials could vary from 1 ppb to $680 \mathrm{ppb}^{26}$. In our study, among 30 raw feed materials, maximum level of aflatoxin was found to be $74.31 \mathrm{ppb}$ and mean value was $22.75 \mathrm{ppb}$ which contradicts with the result found by G Fareed in 2014 where highest contamination value and mean value were $165 \mathrm{ppb}$ and $74.4 \mathrm{ppb}$, respectively among 114 raw feed materials 27 .

Hussein et. al. (2001) demonstrated that $25 \%$ of crops of the world may be contaminated with varying types of fungi and their toxins which could pose severe economical and health threat 28 . In our study, the mean value of aflatoxin in maize is $23.47 \mathrm{ppb}$ which is much lower than the result found by Becha et. al. (2013) ${ }^{26}$.

According to US Food and Drug Administration, the acceptable limit of aflatoxin in food and feed is $20 \mathrm{ppb}$ and any food or feed exceeding this limit should be considered as unsuitable for consumption by animal or human. According to our study, $21 \%$ of finished feed samples $(n=12)$ and raw feed samples $(n=9)$ had aflatoxin concentration above the acceptable limit employed by USFDA which is a matter of serious concern.

Contamination with pathogenic fungi as well as with mycotoxin can be happen in any step of pre harvesting or post harvesting, processing, handling, shipment and storage under favorable environmental conditions ${ }^{29}$. Comparatively high relative humidity, high temperature and moisture with low aeration, all accelerate the growth of pathogenic fungi and the production of aflatoxin in sub-tropical region like Bangladesh. In monsoon season, the amount of moisture is high in environment which influence the propagation of these mold and fungi. Sometimes farmer stock raw soybean, maize and other raw grains and seed for longer period for extra profit in future that also facilitate the fungal development $18,30-31$.

Practically, it's hard to prevent aflatoxin contamination in food and feed commodities but several measures could control the severity of this aflatoxicosis problem. Routine monitoring throughout the entire process of harvesting, processing and storage could lessen this problem a lot. Besides, detoxification methods can be applied to the intoxicated feed and feedstuffs. Feed and feed materials should not be stored for longer period before use, adequate post-harvest drying of seed and grain should be done. Feed and grains should be stored in a dry and cool place where humidity is low. Feed and feed materials should be purchased from a reliable source where they are handled carefully.

\section{Conclusion}

As total eradication of toxigenic fungi and their toxin is not possible, some selective approaches can be a help in aûatoxin management, like, resistant varieties development, biological control of these fungi and aflatoxin, integrated agronomy practices throughout the whole process of grain harvest, shipping, storage, feed manufacturing, and its formulation. This whole study emphasizes the need of proper surveillance and constant monitoring programs for aflatoxin free food and feedstuffs for human and animal.

\section{Competing interests}

The authors declare that they have no competing interests.

\section{Acknowledgement}

We thank Kazi Farms Poultry Laboratory for laboratory facilities and technical assistance.

\section{Reference}

1. Beg, M. U., Al-Mutairi, M., Beg, K. R., Al-Mazeedi, H. M., Ali, L. N., \& Saeed, T. (2006). Mycotoxins in poultry feed in Kuwait. Archives of Environmental Contamination and Toxicology, 50: 594-602.

2. Dalcero, A., Magnoli, C., Luna, M., Ancasi, G., Reynoso, M. M., Chiacchiera, S., et al. (1998). Mycoflora and naturally occurring mycotoxins in poultry feeds in Argentina. Mycopathologia, 141: 37-43.

3. Oliveira, G. R., Ribeiro, J. M., Fraga, M. E., Cavaglieri, L. R., Direito, G. M., Keller, K. M.,et al. (2006). Mycobiota in poultry feeds and natural occurrence of aflatoxins, fumonisins and zearalenone in the Rio de Janeiro State, Brazil. Mycopathologia, 162: 355-362. 
4. JE Smith; G Solomons; C Lewis; JG Anderson. Nat Toxins, 1995, 3: 187192.

5. Khalil A., Alkhalaileh N.I., Anas A., Abdur-Rahman A. Al-Fataftah and Sager M.H. (2015) Occurrence of afaltoxin B1 in poultry feed and feed ingredient in Jordan using ELISA and HPLC. American-Eurasian Journal of Toxicological Sciences 7(4): 316-320.

6. Anjum MA, Khan SH, Sahota AW, Sardar R (2012). Assessment of aflatoxin B1 in commercial poultry feed and feed ingredients. The Journal of Animal and Plant Sciences, 22: 268-272.

7. Akande KE, Abubakar MM, Adegbola TA, Bogoro SE (2006). Nutritional and health implications of mycotoxins in animal feeds: a review. Pakistan Journal of Nutrition, 5: 398-403.

8. CAST (2003). Mycotoxins: Risk in Plants, Animals and Humans. Task Force Report No. 139, Council for Agricultural Science and Technology (CAST), Ames, Iowa, USA.

9. Hussain Z, Muhammad ZK, Ahrar K, Ijaz J, Muhammad KS, Sultan M, Muhammad RA (2010). Residues of aflatoxin B1 in broiler meat: Effect ofage and dietary aflatoxin B1 levels. Food and Chemical Toxicology, 48: $3304-3307$

10. Giacomini, L., Fick, F. A., Dilkin, P., Mallmann, C. A., Rauber, R. H., \& Almeida, C. (2006). Desempenho e plumagem de frangos de corte intoxicados por aflatoxinas. Ciência Rural, 36(1), 234-239 (in Portuguese).

11. Sklan, D., Klipper, E., \& Friedman, A. (2001). The effect of chronic feeding of diacetoxyscirpenol, T-2 toxin and aflatoxin on performance, health, and antibody production in chicks. The Journal of Applied Poultry Research, 10: 79-85.

12. G. Cortés, M. Carvajal, I. Méndez-Ramírez, E. Ávila-González, N. ChilpaGalván, P. Castillo-Urueta, et al.Identification and quantification of aflatoxins and aflatoxicol from poultry feed and their recovery in poultry litter. Poultry Science, 89 (2010), pp. 993-1001.

13. Herzallah, S. M. (2009). Determination of aflatoxins in eggs, milk, meat and meat products using HPLC fluorescent and UV detectors. Food Chemistry, 114: 1141-1146.

14. A.A. Salwa, W. Anwer Effect of naturally contaminated feed with aflatoxins on performance of laying hen and the carryover of aflatoxin B1 residues in table eggs. Pakistan Journal of Nutrition, 8 (2) (2009), pp. 181-186.

15. Wild, C.P. and P.C. Turner, 2002. The toxicology of aflatoxins as a basis for public health decisions. Mutagenesis, 17: 471-481.

16. International Agency for Research on Cancer (IARC), 2002. Traditional Herbal Medicines, Some Mycotoxins, Napthalene, and Styrene. Monographs on the Evaluation of Carcinogenic Risks to Humans. IARC, pp. $82-171$.
17. D'Mello, J.P.F. (2000). Antinutritional Factors and Mycotoxins. Farm Animal Metabolism and Nutrition. Wallingford, UK, CAB International, pp. $383-403$.

18. Roy M, Harris J, Afreen S, Deak E, Gade L, Balajee SA et al (2013) Aflatoxin contamination in food commodities in Bangladesh. Food Addit Contam Part B Surveill 1:17-23.

19. RM Azab; WM Tawakkol; AM Hamad; MK Abou-Elmagd; E-AH M; RM K. Egipt J of natural toxin, 2005, 2: 39-56.

20. FAO, Worldwide Regulations for Mycotoxins in Food and Feed in 2003, in: F.a.A. Organization (Ed.) vol 81, FAO Food and Nutrition Paper, Rome, Italy, 2004.

21. Kehinde, M.T., F. Oluwafemi, E.E. Itoandon, F.A. Orji, and O.I. Ajayi. 2014. Fungal Profile and Aflatoxin Contamination in Poultry Feeds Sold in Abeokuta, Ogun State, Nigeria. Nigerian Food J. 32:73-79.

22. Aycicek, H., Aksoy, A. and Saygi, S. (2005). Determination of aûatoxin levels in some dairy and food products which are consumed in Ankara, Turkey. Food Control 16(3): 263-266.

23. S Rawal; JE Kim; R Coulombe. Aflatoxin B1 in poultry: toxicology, metabolism and prevention. Jr. Res Vet Sci, 2010, 89: 325-331.

24. Nemati Z, Janmohammadi H, Taghizadeh A, Maleki H, Nejad Mogaddam GH, Arzanlou M (2014a) Occurrence of aflatoxins in poultry feed and feed ingredients from north western Iran. Eur J Zool Res 3:56-60.

25. Beg MU, Al-Mutairi M, Beg KR, Al-Mazeedi HM, Ali LN, Saeed T (2006). Mycotoxin in poultry feed in Kuwait. Archives of Environmental Contamination and Toxicology, 50: 595-602.

26. Becha, B. B. and Devi, S.S. (2013). Aflatoxin levels in feeds and feed ingredients of livestock and poultry in Kerala. Journal of Veterinary medicine and Animal Science, 44: 76 - 78.

27. Fareed G, Anjum MA and Ahmed N (2014). Determination of Aflatoxin and Ochratoxin in poultry feed ingredients and finished feed in humid semi-tropical environment. Journal of Advanced Veterinary Animal Research, 1(4), 201-207.

28. Hussein, H. and J. Brasel, 2001. Toxicity, metabolism and impact of mycotoxins on human and animals. Toxicology, 167: 101-134.

29. Giray, B., Girgin, G., Engin, A. B., Aydin, S. and Sahin, G. 2007. Aflatoxin levels in wheat samples consumed in some regions of Turkey. Food Control 18: $23-29$.

30. Moss MO (2002) Mycotoxins review. 1. Aspergillus and Penicillium. Mycologist 16:116-119.

31. Dersjant-Li, Y., Verstegen, M. W. A. And Gerrits, W. J. J., 2003. The impact of low concentrations of aflatoxin, deoxynivalenol or fumonisin in diets on growing pigs and poultry. Nutr. Res. Rev., 16: 223-239. 